\title{
Обеспечение технологического качества на производстве
}

\author{
А. Генцелев
}

УДК 658.5 | ВАК 05.27 .06

\begin{abstract}
Для обеспечения надлежащего уровня качества продукции традиционно предпринимают действия, которые направлены на построение определенной организационной инфраструктуры и затрагивают все аспекты деятельности предприятия. Другими словами, это многофакторная задача, к решению которой необходимо подходить комплексно. О современных подходах к контролю качества электронных изделий в процессе производства и оборудовании, с помощью которого они реализуются, рассказывается в статье.
\end{abstract}

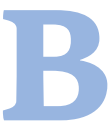

приборостроении задача обеспечения качества изделий электронной техники - одна из ключевых. Снижение качества и надежности выпускаемой продукции подрывает авторитет производителя, уменьшает прибыль и количество потенциальных заказов. Проведение ремонтов, связанных с неоднократной заменой компонентов, снижает надежность приборов и увеличивает вероятность проведения гарантийных ремонтов у потребителя. Учитывая широкую географию продаж, затраты на проведение подобных ремонтов могут быть настолько значительны, что сделают производство убыточным, особенно при длительных гарантийных сроках. Высокая трудоемкость проведения ремонтов приборов повышает их себестоимость и отпускную стоимость, снижая конкурентоспособность на рынке.

С развитием технологий "Индустрии 4.0", в том числе искусственного интеллекта, современные предприятия в своей политике обеспечения качества стремятся переходить от поиска, устранения и выявления технологических причин возникновения дефектов к прогнозированию их возникновения и заблаговременной разработке предупреждающих мер. Конечно, предотвратить возникновение дефекта гораздо эффективнее, чем выполнять последующий его поиск и ремонт изделия. Но даже такой подход из-за многофакторности системы обеспечения качества не гарантирует отсутствия дефектов. Поэтому, помимо предупреждающих мер, на

Центр технологий и инноваций ООО «Остек-СМТ», главный специалист, info@ostec-group.ru. предприятии должна действовать система производственного контроля.

Основные виды дефектов, которые встречаются на производстве в целом и в приборостроении в частности, можно разделить на тригруппь:

- конструкторские дефекты;

- дефекты покупных изделий / комплектующих;

- технологические дефекты.

\section{КОНСТРУКТОРСКИЕ ДЕФЕКТЫ}

Конструкторские дефекты - это несоответствие требованиям технического задания или установленным правилам разработки (модернизации) продукции. Они являются следствием несовершенства конструкции и ошибок при конструировании. Причины таких дефектов могут быть различными: от неправильного выбора материалов и компонентов до некорректной разводки платы или схемотехнических ошибок.

Ошибки разработки должны быть выявлены на этапах приемки конструкторской документации, технологической подготовки производства и изготовления опытных образцов (рис. 1).

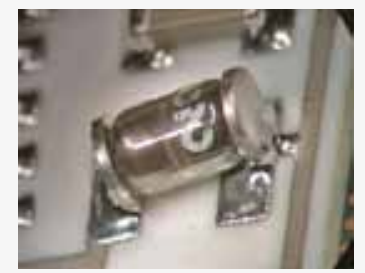

a)

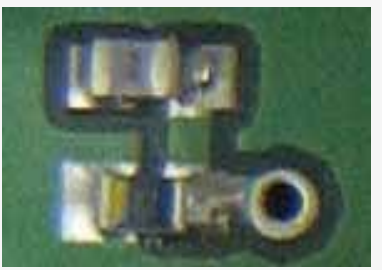

б)

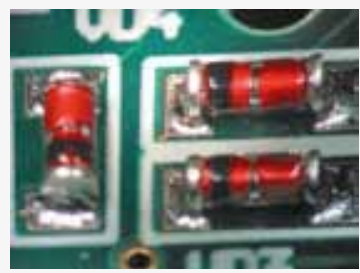

в)

Рис. 1. Примеры конструкторских дефектов: а - близкое расположение дорожки к площадке; 6 - близость переходного отверстия к контактной площадке; в - неправильная конструкция контактных площадок 


\section{ДЕФЕКТЫ ЭЛЕКТРОННЫХ КОМПОНЕНТОВ, ПОКУПНЫХ ИЗДЕЛИЙ И МАТЕРИАЛОВ}

Данный тип дефектов возникает при использовании некачественных комплектующих при сборке изделия (рис. 2)

Для предупреждения поступления в производство дефектных (несоответствующих по электрическим параметрам) компонентов, комплектующих и материалов необходимо следующее

- разработка, внедрение и поддержание в актуальном состоянии нормативных документов (например, стандартов предприятий), регламентирующих применение комплектующих (ограничительных перечней);

- организация постоянной работы по квалификации производителей и поставщиков для поддержания ограничительных перечней в актуальном состоянии;

- при приемке конструкторской документации контроль применения только изделий, включенных в утвержденный ограничительный перечень;

- организация проведения входного контроля покупных изделий в соответствии с программами и методиками, разработанными в процессе квалификации производителей и поставщиков.

Крайне полезным будет и организация системы прослеживаемости используемых комплектующих, позволяющей вести статистику отказов компонентов, что даст возможность при обнаружении систематических дефектов вернуть все печатные узлы их поставщику (производителю) для замены дефектных компонентов.

\section{ТЕХНОЛОГИЧЕСКИЕ ДЕФЕКТЫ}

Технологические дефекты - это несоответствие изделия требованиям нормативной документации на изготовление или поставку продукции. Данные дефекты обычно возникают при нарушении технологического процесса при производстве, неудовлетворительном состоянии оборудования, нарушении условий хранения.

Наиболее распространенные технологические дефекты в приборостроении:

- внутренние повреждения или деформация компонента;

- внутренние дефекты паяного соединения;

- отсутствие компонента;

- смещение компонента;

- «надгробный камень»;

- ошибочный типономинал;

- непропай;

- неправильная форма галтели;

- короткое замыкание

- шарики припоя;

- перепутанная полярность;

- повреждения выводов компонентов.

На возникновение технологических дефектов влияют практически все производственные параметры, в том числе:

- уровень производственной дисциплины;

- технологические режимы;

- условия окружающей среды;

- состояние оборудования

- условия хранения и транспортировки изделий и комплектующих;

- уровень квалификации персонала.

Очевидно, что для обеспечения качества на производстве недостаточно выполнить большой ряд сложных мероприятий. Необходимо также обеспечить поддержание всех параметров технологического процесса после достижения запланированного уровня качества. Постоянство параметров производства - необходимое условие повторяемости технических характеристик выпускаемых изделий. Такая повторяемость должна быть обеспечена в том числе за счет повторяемости параметров технологических процессов. Строгая технологическая дисциплина

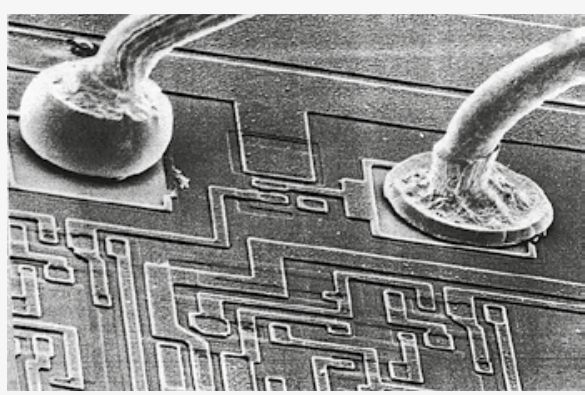

a)

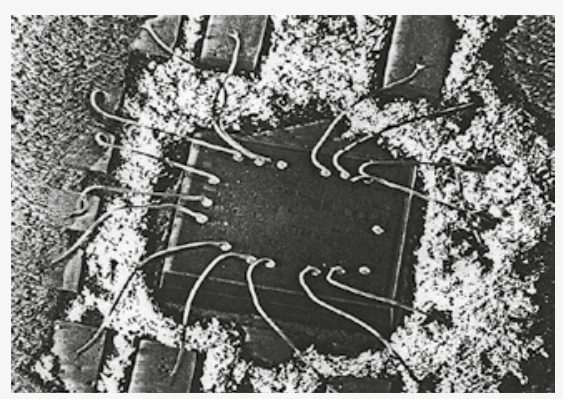

б)

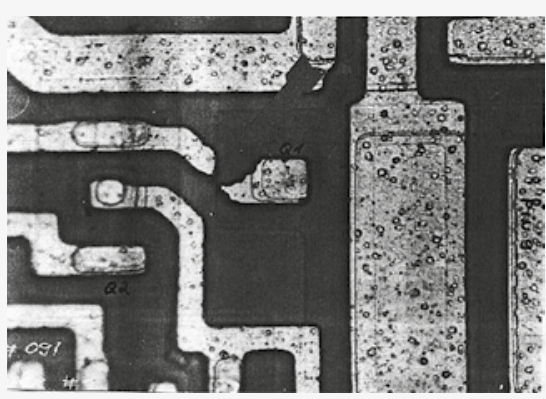

B)

Рис. 2. Примеры дефектов покупных изделий: а - дефект соединения кристалла с проводником; б - дефект корпусирования и избыточная длина проводников; в - дефект травления 
должна достигаться за счет первоклассного оборудования, квалифицированного персонала и современной организации производства.

\section{КАКОЙ УРОВЕНЬ КАЧЕСТВА СЧИТАЕТСЯ ДОПУСТИМЫМ?}

Здесь не может быть единого значения или «золотой середины» для всех. Каждое предприятие вправе устанавливать свои стандарты качества в зависимости от типа и применения выпускаемых изделий. На слуху сейчас концепция "Шесть сигм" с ее 3,4 дефектами на миллион возможных, но она подразумевает комплексный подход к обеспечению качества на выходе каждой из операций, входящих в производственный цикл, что в силу разных причин удается далеко не всем. Поэтому чаще можно услышать упоминания про 10 или 100 рpm, что составляет 0,001 и 0,01\% дефектов соответственно. Между этими показателями разница весьма существенна - в 10 раз.

Попробуем сделать простейший расчет, пусть на слегка грубом примере, чтобы увидеть разницу в экономии. Для расчета возьмем производство с годовым объемом выпуска 10000 приборов стоимостью по 100000 руб. каждый. Конструкция расчетного печатного узла состоит из 1000 компонентов. Среднее количество точек пайки среднестатистически равно трем на каждый компонент, то есть на печатном узле 3000 паяных соединений. Важно! Для расчета мы принимаем уровень конструкторских дефектов и дефектов, связанных с некачественными комплектующими, равным «0».

\section{КОЛИЧЕСТВО ДЕФЕКТОВ ПРИ ПОДХОДАХ 100 И 10 РРМ}

Потенциальное количество дефектных паяных соединений при 100 рpm:

$$
10000 \times 3000 \times 100 / 1000000=3000 \text {. }
$$

Это означает, что 3000 паяных соединений могут иметь дефекты, таким образом, теоретически до 30\% собранных изделий могут оказаться с браком.

Примерная трудоемкость локализации дефектов на плате с 1000 компонентов (без автоматической оптической инспекции (АОИ)) составляет 4 ч. При стоимости нормо-часа 1000 руб. стоимость ремонтов в партии будет равна:

$$
3000 \times 1000 \times 4=12000000 \text { pуб. }
$$

Потенциальное количество дефектных паяных соединений при 10 рpm:

$10000 \times 3000 \times 10 / 1000000=300$.
При тех же значениях трудоемкости локализации дефектов и стоимости нормо-часа стоимость ремонтов в партии составит:

$$
300 \times 1000 \times 4=1200000 \text { py } 6
$$

12 млн руб. при 100 ррm или 1,2 млн руб. при 10 рpm разница более чем в 10 млн руб. Весьма ощутимо.

Мы взяли в качестве примера случаи, когда изделие еще не вышло за пределы предприятия, и его неработоспособность была выявлена на этапе производства или функционального контроля. А если изделие успешно прошло испытания и отправилось к заказчику? Технологические дефекты, если они не были выявлены в процессе сборки или тестирования изделия, проявляются, какправило, в начальный период эксплуатации, что влечет за собой выполнение гарантийных обязательств. В этом случае к затратам на ремонт добавляются командировочные расходы, которые, учитывая размеры нашей страны, могут составлять десятки и даже сотни тысяч рублей, и разница между 10 и 100 ррт становится еще ощутимее.

Понятно, что отпускная цена на изделие чаще всего предусматривает расходы на проведение гарантийных работ, но предприятие при недостаточном уровне обеспечения качества теряет собственные средства, а как это назвать - "расходы» или «упущенная выгода» - большой роли не играет.

Таким образом, напрашиваются следующие выводы:

- уровень дефектности 0,01\% (100 ррm) и более приводит к существенным финансовым потерям предприятия и снижает уровень его репутации;

- обеспечение производства прогрессивными технологиями контроля качества является необходимым условием для достижения высоких показателей чистой прибыли и уровня конкурентоспособности;

- налаженный комплекс обеспечения качества может окупиться уже в первый год.

\section{СПОСОБЫ ВЫЯВЛЕНИЯ ТЕХНОЛОГИЧЕСКИХ ДЕФЕКТОВ И ИХ ОГРАНИЧЕНИЯ}

На текущий момент существуют два основных и наиболее распространенных способа поиска технологических дефектов: визуальный контроль (или оптическая инспекция) и рентгеновский контроль. Причем именно для выявления дефектов больше используется первый, а второй по большей части служит для отладки технологического процесса. Но тенденция ко все большему использованию компонентов со скрытыми под корпусом выводами делает использование АОИ менее эффективным, а рентгеновский контроль более востребованным как раз для поиска дефектов.

Известно, что разные методы контроля хороши каждый для своих задач. Например, оптические системы 
контроля неспособны выявить пустоты в паяном соединении и другие скрытые или невидимые глазу дефекты. Для этого нужен рентген. С его помощью можно обнаружить наибольшее количество дефектов, но вряд ли кому-то придет в голову использовать его для поиска «надгробного камня», наличия / отсутствия компонента или шариков припоя.

У названных методов контроля, помимо функциональных, существуют еще аппаратные и программные ограничения самих систем.

В АОИ это:

- длительные подготовка и отладка программ инспекции (при том, что скорость самой инспекции обычно высокая);

- теневые зоны (например, расположение высоких компонентов рядом с низкими может затруднять проведение инспекции последних);

- невозможность измерения высот на плате;

- невозможность определения формы галтели;

- невозможность инспекции боковых сторон компонентов.

У систем рентгеновского контроля самое существенное ограничение - скорость инспекции, так как большинство операций выполняется оператором. Также может быть затруднена инспекция плат с двухсторонним монтажом из-за наложения изображений компонентов друг на друга при "просвечивании" рентгеновским излучением. Необходимо помнить, что не все компоненты способны выдержать длительное рентгеновское излучение (подробнее в статье И. Проказова «Воздействие рентгеновского излучения на электронные устройства и компоненты»").

Разумеется, у каждой системы АОИ или рентгеновского контроля есть свои отличия и ограничения, зависящие от ее класса и технических характеристик, выше мы показали наиболее общие, свойственные большинству систем на рынке.

Получается, что так и нет "универсальной таблетки" от всех болезней или, вернее, способа инспекции, способного обеспечить и высокую скорость, и обнаружение всех дефектов на печатных узлах, выходящих со сборочной линии.

Значит, ограничение одной системы является достоинством другой. А если системы объединить? Тогда ограничения могут быть компенсированы, а совокупность функциональных возможностей даст синергический эффект.

Именно так решили в компании Viscom и представили рынку комбинированную систему X7056-ІІ, сочетающую в себе богатые возможности оптической инспекции и рентгеновского контроля и одновременно нивелирующую ограничения этих двух технологий.

\footnotetext{
* Вектор высоких технологий, 2014, № 8 (13).
}

\section{- Самое существенное ограничение систем рентгеновско-} го контроля?

- Скорость инспекции.

- Самое существенное ограничение систем АОИ?

- Невозможность видеть скрытые дефекты.

- Ключевое достоинство систем рентгеновского контроля?

- Возможность видеть скрытые дефекты.

- Ключевое достоинство систем АОИ?

- Скорость инспекции.

\section{СИСТЕМА АВТОМАТИЧЕСКОЙ 3D-РЕНТГЕНОСКОПИИ И ОПТИЧЕСКОЙ 3D-ИНСПЕКЦИИ Х7056-II}

Viscom X7056-II (рис. 3) - это уникальное решение, которое сочетает автоматическую оптическую инспекцию с высоким разрешением и автоматическую рентгеноскопию (АРИ). Объединение двух видов контроля в одном корпусе позволило получить фантастическую по своим возможностям систему, способную обеспечить практически 100\%-ный контроль качества печатных узлов после пайки.

В цикле инспекции могут быть задействованы как обе секции - АОИ и АРИ, - так и каждая из них отдельно. Если проведение одного из видов контроля для какоголибо изделия не требуется, незадействованная секция может работать просто "на проход". Секции разделены

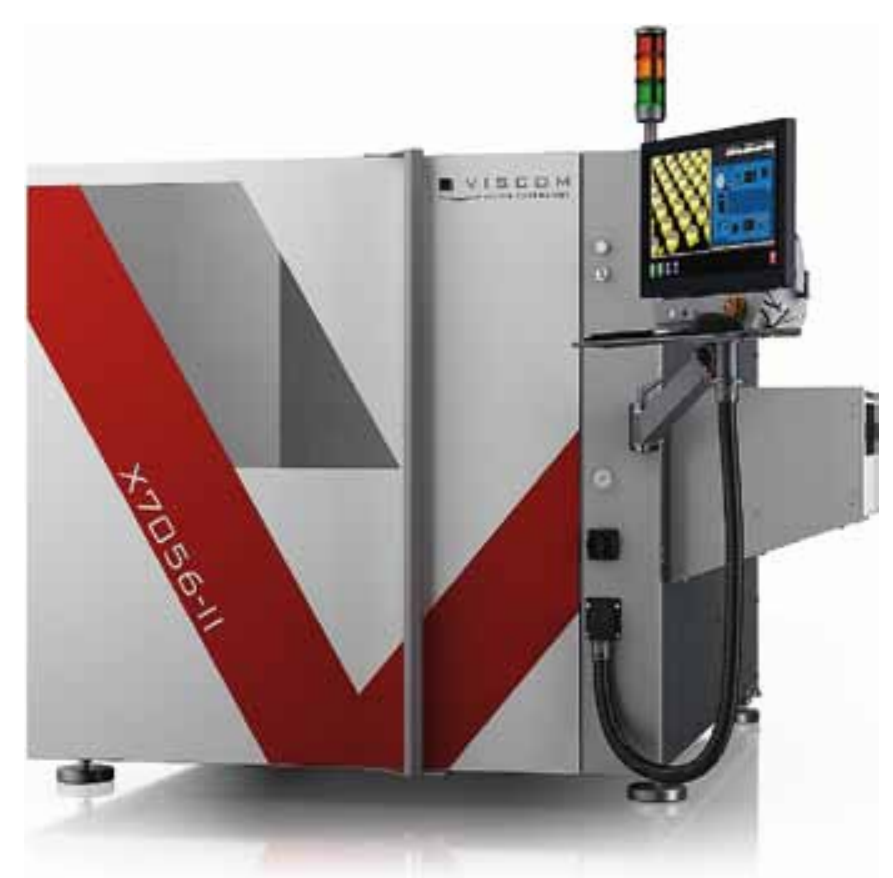

Рис. 3. Система автоматической 3D-рентгеноскопии и оптической инспекции Viscom X7056-II 


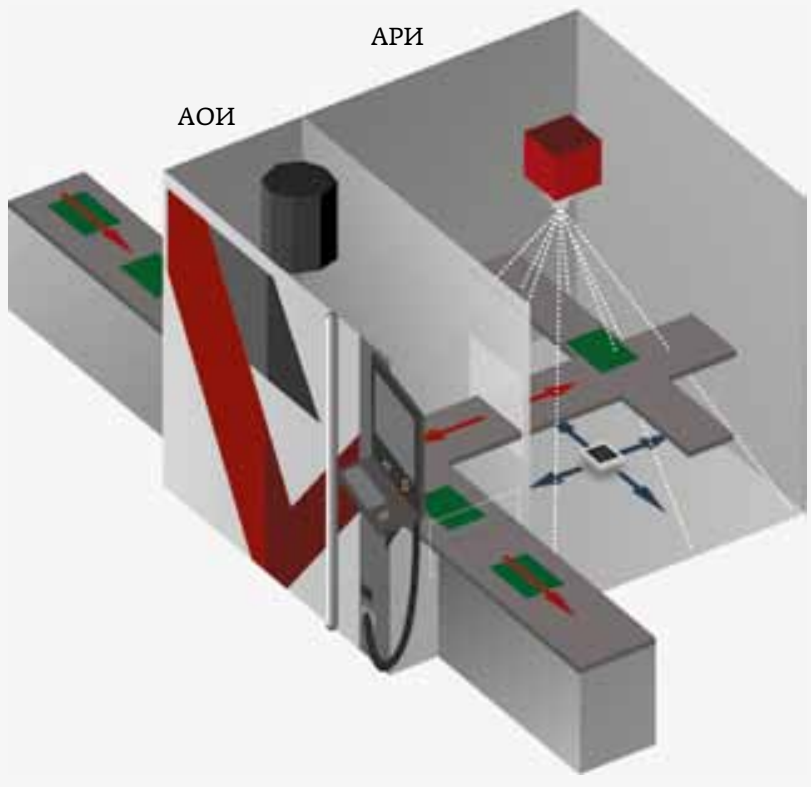

Рис. 4. Устройство системы Viscom X7056-II

защитной автоматической перегородкой, которая открывается только в момент перемещения платы между ними.

Работа X7056-II построена следующим образом (рис. 4):

- плата А поступает по конвейеру в секцию АОИ, где осуществляется полный оптический контроль качества ее сборки;

- после завершения оптического контроля плата А перемещается в секцию АРИ;

- плата Б поступает в секцию АОИ;

- система автоматически начинает рентгеновский контроль выборочных участков платы А;

- параллельно с этим происходит полный оптический контроль платы Б;

- после завершения операций плата А выходит из секции АРИ и поступает на выход системы, а плата Б занимает ее место, переместившись из зоны АОИ ит.д.

Так как рентгеновский контроль всего печатного узла не является обязательным и занимает длительное время, Х7056-ІІ производит инспекцию только выборочных участков платы, указанных при подготовке рабочей программы. Логично, что такими участками на печатном узле будут наиболее критичные элементы и компоненты со скрытыми выводами. Эти же компоненты предварительно можно проконтролировать при помощи АОИ. В табл. 1 представлены предпочтительные способы инспекции для определения дефектов различных видов для некоторых типов корпусов компонентов. Разные виды инспекции, использованные в одной системе, не исключают, а дополняют друг друга.

Разделение печатных узлов на "прошедшие" и "непрошедшие» контроль происходит с учетом проведения обоих видов инспекции. Даже если плата прошла проверку в АОИ, но АРИ показал в ней наличие дефектов, она будет перемещена в отбракованные. Оператору на ремонтной станции для проведения анализа будут доступны все изображения, полученные из системы, - как снимки с АОИ, так и из АРИ.

Понятно, что объединить две системы в одну - еще не значит обеспечить гарантированное выявление дефектов. Тут важно не то, что две системы объединены в одну, а то, какие именно это системы, насколько эффективно они могут работать. Компания Viscom пошла по пути реализации оптимального для конкретного исполнения оборудования функционала, для каждой из секций.

\section{СЕКЦИЯ АРИ}

Для проведения рентгеноскопии в системе применяется рентгеновская трубка закрытого типа (рис. 5) с максимальным напряжением 130 кВ и силой тока 300 мкА. Такие характеристики достаточны и оптимальны для

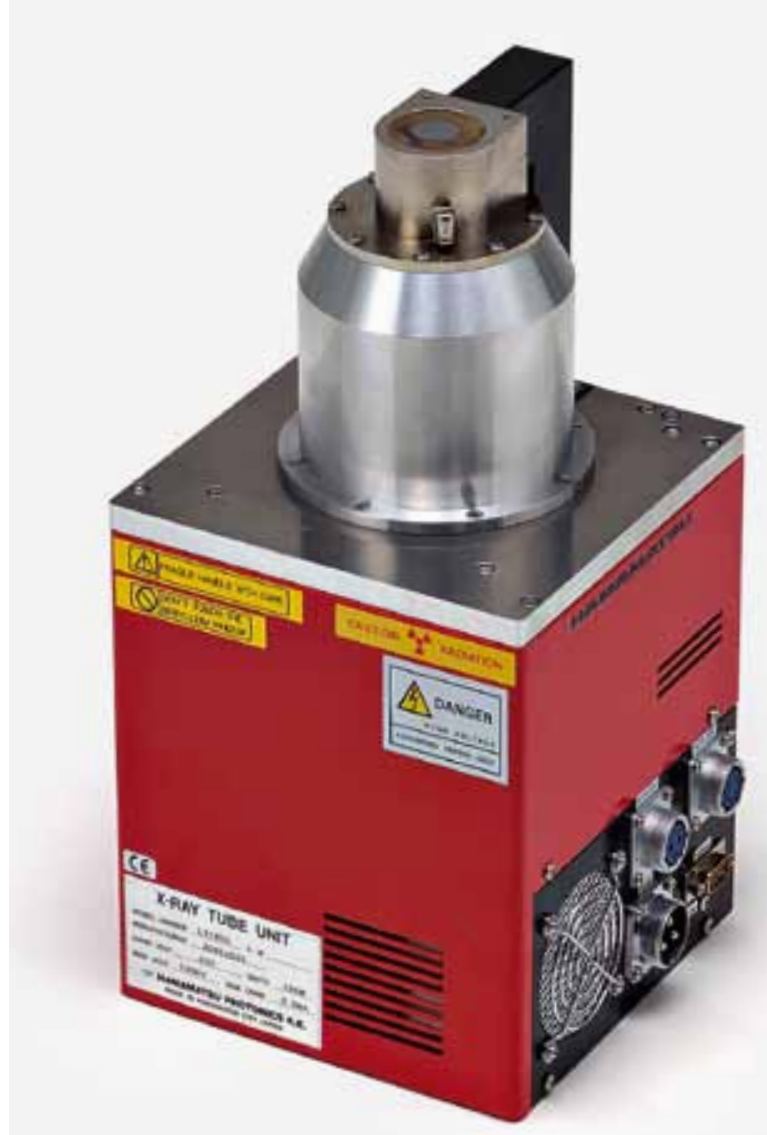

Рис. 5. Рентгеновская трубка системы Viscom X7056-II 
Таблица 1. Предпочтительные способы инспекции для определения дефектов различных видов для ряда типов корпусов компонентов

\begin{tabular}{lllllll} 
& Наличие & Позиционирование & Перемычки & Пустоты & Полярность Пайка \\
ВСА & АОИ & АОИ & АРИ & АРИ & АОИ & АРИ \\
\hline Flip-chip & АОИ & АОИ & АРИ & АРИ & АОИ & АРИ \\
\hline MLF/QFN & АОИ & АОИ & АРИ & АРИ & АОИ & АРИ \\
\hline QFР & АОИ & АОИ & АОИ/АРИ & АРИ & АОИ & АОИ/АРИ \\
\hline ТНТ & АОИ & АОИ & АОИ/АРИ & АРИ & - & АРИ \\
\hline Чип-компоненты & АОИ & АОИ & АОИ/АРИ & АРИ & АОИ & АОИ/АРИ \\
\hline РLСС & АОИ & АОИ & АОИ/АРИ & АРИ & АОИ & АОИ/АРИ \\
\hline SОТ & АОИ & АОИ & АОИ/АРИ & АРИ & АОИ & АОИ/АРИ \\
\hline
\end{tabular}

большинства задач при проведении контроля печатных узлов. Выбор в пользу закрытой трубки со встроенным генератором излучения был сделан исходя из соображений производительности и минимизации времени простоя рентгеновской секции - отсутствие необходимости замены катодов и проведения операций откачки воздуха из трубки оказывают на это непосредственное влияние.

Используемые цифровые детекторы с глубиной серого цвета 14 бит и разрешением 8/10 / 20 мкм / пиксель позволяют инспектировать самые маленькие на сегодняшний день корпуса и автоматически оптимизировать скорость инспекции в зависимости от сложности и размеров компонента или потенциального дефекта.

В системе возможны три типа конфигураций детекторов:

- один неподвижный детектор: 2D-инспекция с вертикальной съемкой;

- один детектор на подвижном столе: 2D-инспекция с вертикальной съемкой, 2,5D-инспекция - боковые снимки под необходимым углом и 3D-инспекция (опция planar CТ);

- система из пяти детекторов: 2D-инспекция с вертикальной съемкой, 2,5D-инспекция - боковые снимки под определенными углами и 3D-инспекция (опция planar CT).

Planar CT - косоугольная компьютерная томография, которая позволяет получать послойные срезы и проводить объемный анализ полученных снимков. Это дополнительная функция, доступная для Х7056-ІІ. При инспекции двухсторонних сложных плат, где компоненты с разных сторон могут перекрывать друг друга на рентгеновских снимках, функция planar Ст становится незаменимой. Она делает все скрытые и неявные детали отчетливо видными и пригодными для оценки. Полученный в planar СТ срез или вид определенного слоя позволяет провести точную оценку изображения без наложения элементов с других слоев. Процесс программирования упрощается, а количество ложных срабатываний уменьшается.

\section{СЕКЦИЯ АОИ}

В АОИ системы X7056-ІІ используется высокопроизводительный оптический модуль ХМ (рис. 6), применяемый в самых современных установках 3D AOИ компании Viscom. Благодаря высокой скорости захвата и обработки изображений до 3,6 Гпикс / с и большому полю обзора 40 × 40 / 50 × 50 мм инспекционные модули ХМ являются одними из самых быстрых на рынке. Уникальная конструкция модуля камер с возможностью переключения разрешения, а также всесторонняя четырехцветная

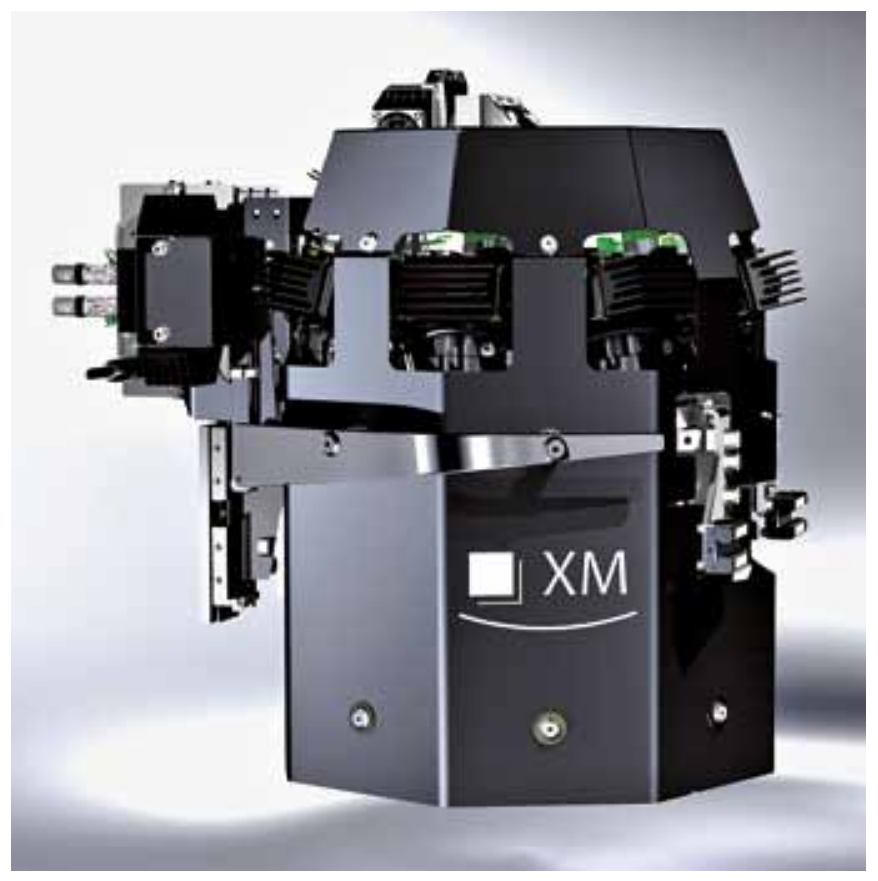

Рис. 6. Высокопроизводительный оптический модуль ХМ 
светодиодная RGBW-подсветка обеспечивают оптимальное качество изображения в процессе работы. Полноценная верхняя черно-белая камера с разрешением в 25 Мп способна проводить инспекцию сверхмалых компонентов 03015 (300×150 мкм). Четырехцветная подсветка и специальные алгоритмы обработки изображений, несмотря на использование черно-белой камеры, позволяют получать качественные цветные изображения.

В дополнение к верхней камере в АОИ можно использовать также четыре или восемь камер, расположенных под разными углами. Это означает, что систему можно настроить на автоматический поиск различных дефектов не только по изображениям с верхней камеры, но и с угловых. Только так можно обеспечить полноценный контроль всего спектра возникающих дефектов. Например, восемь угловых камер, располагаясь под углами 0, 45, 90, 135, 180, 225, 270, 315 и 360, обеспечивают круговой обзор компонентов, что дает возможность проинспектировать самые труднодоступные участки на плате: при перекрытии выводов высокими компонентами, при наличии повернутых на $45^{\circ}$ корпусов или контроле скрытых выводов компонентов QFN и PLCC. Кроме того, высококачественные снимки с угловых камер (рис. 7) можно использовать на станции верификации для помощи в принятии решения по классификации дефектов.

Также стоит отметить подготовку рабочих программ инспекции. Имея в своем составе богатую библиотеку компонентов, программное обеспечение системы после автоматического анализа платы способно самостоятельно подгрузить из нее необходимые корпуса компонентов
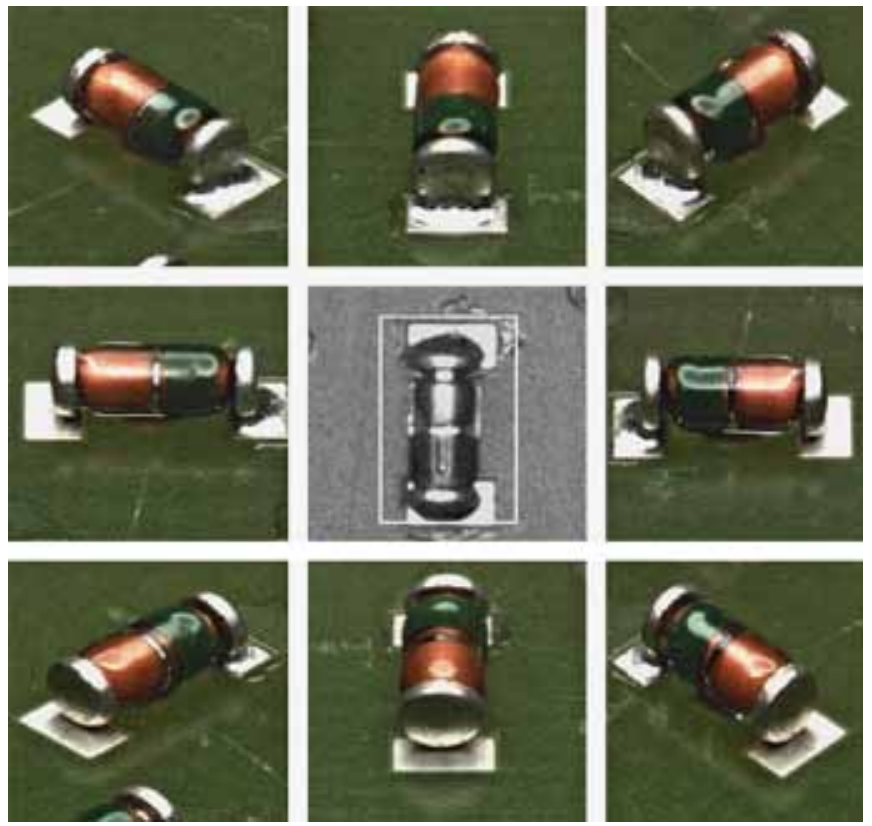

Рис. 7. Снимки компонента на плате с угловых камер модуля XM

со всеми правилами проверки для текущей используемой программы. После этого оператору остается лишь внести необходимые правки, и программа готова для запуска. При работе с нестандартными компонентами можно использовать специальную библиотеку, которая позволяет создавать свои правила проверки и редактировать имеющиеся.

Таблица 2. Ограничения технологий инспекции и решения для их преодоления в X7056-II

\begin{tabular}{lll} 
Секция & Ограничение & Решение \\
\hline АОИ & Теневые зоны & $\begin{array}{l}\text { Угловые камеры } \\
\text { 3D-инспекция }\end{array}$ \\
\cline { 2 - 3 } & Программирование и отладка & Встроенная библиотека компонентов \\
& Угловые камеры \\
& Библиотека алгоритмов проверки
\end{tabular}

Невозможность измерения высот на плате
Невозможность определения формы галтели
Невозможность инспекции боковых сторон компо-
нентов

АРИ Скорость инспекции

3D-инспекция

3D-инспекция

Угловые камеры

3D-инспекция

Закрытая трубка

Выборочная инспекция

Различные конфигурации детекторов

Автоматический алгоритм выполнения

Инспекция двухсторонних плат

Косоугольная томография planar CT 

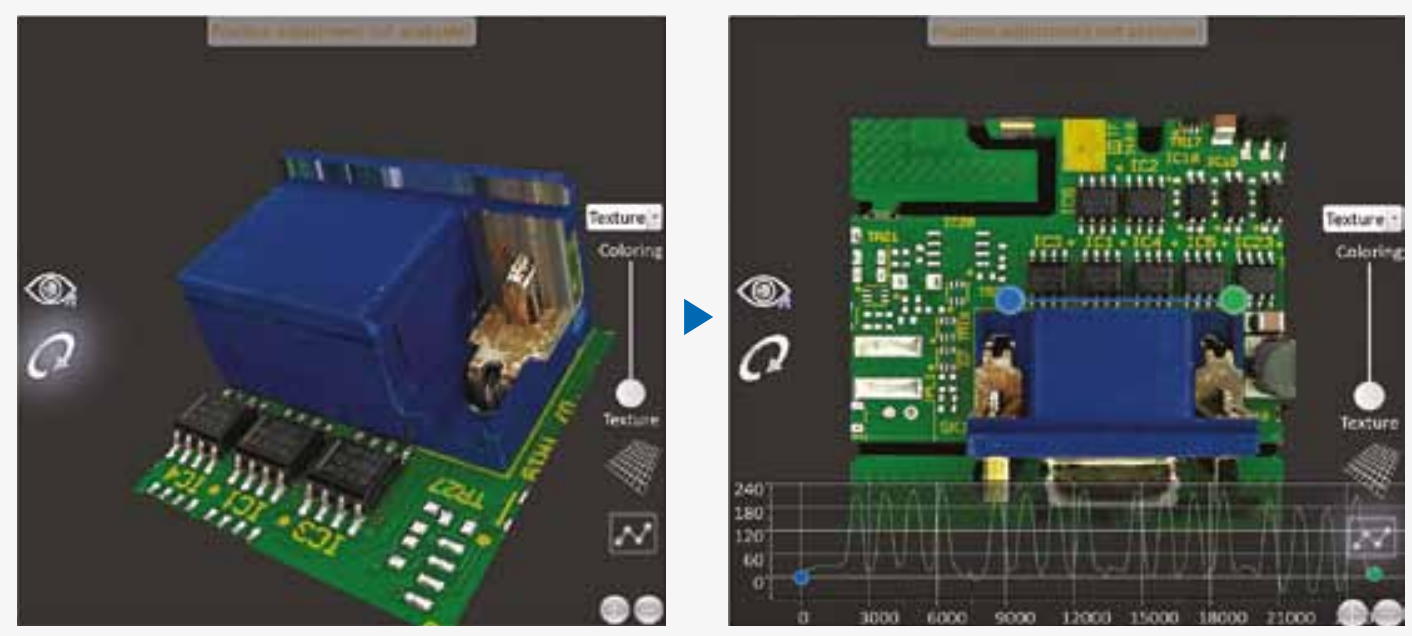

Рис. 8.

Инспекция 3D-модели при плотном монтаже

\section{D-ИНСПЕКЦИЯ}

Технология 3D-инспекции уже стала неотъемлемой частью всех современных АОИ. Система X7056-ІІ способна получать 3D-реконструкции поверхности печатныхузлов с последующим ихавтоматическим измерением, анализом и поиском дефектов. Она может построить высокоточную 3D-модель инспектируемой поверхности. Далее в любой области 3D-модели можно построить профиль сечения, по которому система проведет автоматические измерения и сравнения с эталоном. По итогам сравнения выводятся результаты о малейших отклонениях в форме и объеме галтелей, приподнятых выводах, смещениях и других возможных дефектах.

Система строит 3D-модель инспектируемой поверхности с разрешением по высоте 0,5 мкм. Это дает возможность с высокой достоверностью выявлять даже минимальные отклонения в пайке и точно оценивать объем припоя в галтелях паяных соединений. Применение же угловых камер в процессе реконструкции позволяет исключить так называемый эффект водопада на 3D-изображении, возникающий при использовании лишь верхней камеры, когда теряется информация о текстурах на боковых поверхностях компонентов. 3D-изображения, получаемые на системах AOИ Viscom (рис. 8), содержат максимум информации о компоненте, что полезно при анализе и верификации дефектов, например, при оценке состояния корпуса компонента или возникновении проблем со смачиванием выводов.

Все особенности секций АРИ и АОИ системы X7056-ІІ в рамках одной статьи, к сожалению, рассмотреть невозможно, но даже все вышеописанное позволяет понять, что в данном оборудовании компания Viscom стремится реализовать самые современные технологии и разработки в области инспекции.

Если вернуться немного назад и вспомнить те ограничения, которые свойственны системам рентгеновского контроля и АОИ, можно сделать вывод о том, что в X7056-ІІ эти ограничения снимаются за счет используемых технологий (табл. 2).

Система X7056-II как единое целое - это функционально законченный высокотехнологичный комплекс, не пропускающий ни одного дефекта на производстве и создающий фундамент для построения на предприятии управляемой системы обеспечения качества.

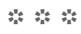

Таким образом, даже неполный обзор технологий, приведенный в статье, показывает, насколько контроль качества в электронном производстве - многофакторная задача. Повторим основные тезисы предлагаемого комплексного подхода к ее решению:

- система обеспечения качества на производстве - это комплекс мероприятий, охватывающий все виды производственной деятельности;

- виды производственных дефектов делятся на три основные группы: конструкторские, дефекты комплектующих и технологические;

- любое, даже не слишком существенное, увеличение качества может принести предприятию выгоду, исчисляемую миллионами;

- с сучетом множества факторов, влияющих на качество и современные тенденции в конструировании печатныхузлов, только совокупность оптического и рентгеновского контроля может дать уверенность в том, что с линии выходят изделия без дефектов;

- для поддержания высокого уровня качества важно не только своевременное выявление дефектов, но и система, позволяющая предотвращать или устранять их на самой ранней стадии.

В одном из следующих номеров журнала мы планируем опубликовать статью, в которой расскажем о системах предотвращения дефектов как части философии управления качеством производства. 